\title{
Capacidade de combinação entre genitores de trigo em duas gerações
}

\section{Combining ability of wheat parents in two generations}

\author{
Elesandro Bornhofen ${ }^{1}$; Giovani Benin ${ }^{2 *}$; Gilvani Matei ${ }^{3}$; \\ Cristiano Lemes da Silva ${ }^{3}$; Eduardo Beche ${ }^{3}$; Eduardo Stefani Pagliosa ${ }^{3}$; \\ Thaís Raquel Hagemann ${ }^{1}$; Cilas Pinnow ${ }^{1}$
}

\section{Resumo}

O trabalho teve como objetivo estimar a capacidade geral e específica de combinação de dez genótipos de trigo em duas gerações $\left(\mathrm{F}_{1}\right.$ e $\left.\mathrm{F}_{2}\right)$ a fim de indicar genitores e combinações híbridas promissoras. Dez genótipos de trigo foram hibridados em forma de dialélo completo, sem os recíprocos, totalizando 45 combinações híbridas. Os híbridos $\mathrm{F}_{1}$, populações $\mathrm{F}_{2}$ e os genitores foram avaliados em delineamento de blocos casualizados com três repetições, em planta espaçada. O efeito da capacidade geral de combinação (CGC) foi superior à capacidade específica de combinação (CEC) em ambas às gerações para todos os caracteres avaliados. O melhor desempenho da CGC para rendimento de grãos por planta (RGP), número de grãos por espiga (NGE), número espigas por planta (NEP) e estatura de planta (EP) foi observado para os genitores Fundacep 50, Pampeano, BRS Figueira e UTF 0605, respectivamente. Combinações híbridas promissoras (elevada magnitude da CEC em ambas as gerações, média elevada para o caráter e pelo menos um dos genitores apresentando CGC desejável) foram selecionadas. A CGC foi positivamente associada com o desempenho dos caracteres $\operatorname{RGP}\left(\mathrm{F}_{1}=0,75\right.$ e $\left.\mathrm{F}_{2}=0,81\right)$, NGE $\left(\mathrm{F}_{1}=0,61\right.$ e $\left.\mathrm{F}_{2}=0,60\right)$ e $\mathrm{EP}\left(\mathrm{F}_{1}=0,99\right.$ e $\left.\mathrm{F}_{2}=0,98\right)$ em ambas as gerações avaliadas, indicando ser um critério confiável para escolha de genitores.

Palavras-chave: Triticum aestivum L., análise dialélica, capacidade geral de combinação, capacidade específica de combinação

\begin{abstract}
The objective of this study were to estimate the general ability and specific combining ability in ten wheat genotypes in two generations $\left(\mathrm{F}_{1}\right.$ and $\left.\mathrm{F}_{2}\right)$ to indicate parents and hybrid combinations that are promising to achieve new favorable combinations. Ten wheat genotypes were hybridized in a complete diallel, without reciprocals, totaling 45 hybrid combinations. $\mathrm{F}_{1}$ hybrids and the $\mathrm{F}_{2}$ populations and parents were planted in a randomized block design with three replicates in spaced plant. The effect of general combining ability (GCA) was greater than specific combining ability (SCA) in both generations, regardless of the traits evaluated. The best performances of the CGC to grain yield per plant (GYP), number of kernels per spike (NKS), number of spikes per plant (NSP) and plant height (PH) were observed for the parents Fundacep 50, Pampeano, BRS Figueira and UTF 0605, respectively. Promising hybrid combinations (high magnitude of SCA in both generations and high average of a traits and at least one parent presenting desirable GCA) were selected. The association of GCA with the performance
\end{abstract}

1 Discentes do curso de Agronomia, Universidade Tecnológica Federal do Paraná, UTFPR, Pato Branco, PR. E-mail: elesandro. bornhofen@gmail.com; thaishagemann@gmail.com; cilaspinnow@gmail.com

2 Prof. do Programa de Pós-Graduação em Agronomia, UTFPR, Pato Branco, PR. E-mail: benin@utfpr.edu.br

3 Discentes de Mestrado do Programa de Pós-graduação em Agronomia, UTFPR, Pato Branco, PR. E-mail: gmatei@nidera.com. br; cristianolemes.utfpr@gmail.com; eduardo_beche@hotmail.com; eduardopagliosa@gmail.com

* Autor para correspondência 
of traits GYP $\left(\mathrm{F}_{1}=0.75 ; \mathrm{F}_{2}=0.81\right)$, NKS $\left(\mathrm{F}_{1}=0.61 ; \mathrm{F}_{2}=0.60\right)$ and $\mathrm{PH}\left(\mathrm{F}_{1}=0.99\right.$ and $\left.\mathrm{F}_{2}=0.98\right)$ showed to be a reliable criterion to choose wheat parents independently of generation tested.

Key words: Triticum aestivum L., diallel analysis, general combining ability, specific combining ability

\section{Introdução}

A escolha de genitores para a formação das populações segregantes é uma etapa crucial para obtenção de êxito em programas de melhoramento genético. Um grande desafio no melhoramento genético de trigo é determinar a intensidade e a forma que o efeito gênico de cada genitor é manifestado nas progênies.

As metodologias de análise dialélica fornecem estimativas de parâmetros úteis à seleção de genitores e entendimento dos efeitos gênicos envolvidos na herança dos caracteres (KRYSTKOWIAK et al., 2009). O método de Griffing (1956) possibilita estimar os efeitos da capacidade geral de combinação (CGC), dependente da concentração de genes predominantemente aditivos, e da capacidade específica de combinação (CEC), relacionada à presença de genes de efeito não aditivos (PFANN et al., 2009).

Em trigo, tem sido relatado a predominância da ação genética aditiva (DHONDE et al., 2000; JOSHI et al., 2004; BERTAN et al., 2009), não aditiva (MENON; SHARNA, 1997; KRYSTKOWIAK et al., 2009) e a presença de ambas, em proporções semelhantes (BARBIERI, et al., 2001; YANG et al., 2002; TOPAL et al., 2004; HASNAIN et al., 2006). Entretanto, a intensificação de seleção de cultivares elite e o estreitamento da base genética tem resultado em reduzida expressão da capacidade de combinação e heterose para caracteres de importância agronômica (KAMALUDDIN et al., 2007; FARSHADFAR; MAHJOURI; AGHASEE, 2008; BERTAN et al., 2009).

Neste contexto, a identificação de variabilidades relacionadas à CGC e CEC é de fundamental importância para a seleção de genitores superiores. $\mathrm{O}$ conhecimento dos efeitos gênicos relacionados à CGC e CEC possibilita o direcionamento dos esforços de melhoramento, com economia de recursos e maiores chances de progresso genético em curto espaço de tempo.

Desta forma, o objetivo do presente trabalho foi estimar a capacidade geral e específica de combinação de dez genótipos de trigo em duas gerações $\left(F_{1}\right.$ e $\left.F_{2}\right)$, a fim de indicar genitores e populações segregantes promissoras.

\section{Material e Métodos}

O experimento foi conduzido em Pato Branco, PR, em área manejada sob sistema plantio direto, com Latossolo Vermelho Distrófico, textura argilosa e relevo ondulado (BHERING et al., 2008). O clima da região é predominante $\mathrm{Cfa}$, de acordo com a classificação de Köppen.

Na safra agrícola de 2006, dez genótipos de trigo (BRS Figueira, BRS Louro, BRS Guamirim, BRS Timbaúva, BRS 208, Pampeano, CD 115, Fundacep 50, Abalone e UTF 0605), escolhidos com base no rendimento de grãos e caracteres de interesse agronômico, foram hibridados em forma de dialélo completo, sem os recíprocos, totalizando 45 combinações. No mesmo ano, uma amostra das sementes $F_{1}$ de cada cruzamento foi semeada em casa de vegetação visando o avanço para a geração $\mathrm{F}_{2}$. As sementes remanescentes foram armazenadas em condições controladas.

Na safra agrícola de 2007, os híbridos $F_{1}$, as populações $F_{2}$ e os genitores foram conduzidos em delineamento de blocos casualizados com três repetições. As parcelas experimentais foram compostas de 20 plantas para os híbridos $\mathrm{F}_{1}$ e 40 plantas cada para os genitores e populações $\mathrm{F}_{2}$, conduzidas espaçadas em $30 \mathrm{~cm}$ entre plantas e entre linhas. 
A adubação de base foi de $250 \mathrm{~kg} \mathrm{ha}^{-1}$ de NPK (8-20-20) e mais $50 \mathrm{~kg} \mathrm{ha}^{-1}$ de nitrogênio aplicado no início do afilhamento. Foi efetuado o controle de doenças de parte aérea, com duas aplicações do princípio ativo Tebuconazole, na dose de 0,75 $\mathrm{L} \mathrm{ha}^{-1}$. Os demais tratos culturais foram realizados de acordo com as recomendações técnicas para a cultura do trigo (COMISSÃO SUL BRASILEIRA DE PESQUISA DE TRIGO, 2004).

Foram avaliados os seguintes caracteres: estatura de planta (EP), pelo comprimento do colmo, em centímetros, desde a superfície do solo até o ápice da inflorescência, excluindo as aristas, número de espigas por planta (NEP), contando individualmente as espigas de cada planta, número de grãos por espiga (NGE), contando o número total de grãos de cada planta e dividido pelo número de espigas, massa de 100 grãos (MCG), em gramas, e rendimento de grãos por planta (RGP), em gramas, obtido pela pesagem da produção de grãos das plantas, trilhadas individualmente.

Os dados foram submetidos à análise de variância individual e geral. As somas de quadrados dos tratamentos foram decompostas em capacidade geral (CGC) e específica (CEC) de combinação. $\mathrm{Na}$ decomposição, foi empregado o Método 2, Modelo B de Griffing (1956), descrito pelo modelo estatístico $\mathrm{Y}_{\mathrm{ij}}=\mathrm{m}+\mathrm{g}_{\mathrm{i}}+\mathrm{g}_{\mathrm{j}}+\mathrm{s}_{\mathrm{ij}}+\varepsilon_{\mathrm{ij}}$, onde: $\mathrm{Y}_{\mathrm{ij}}$ é o valor médio da combinação $(i \neq j)$ ou do genitor $(\mathrm{i}=\mathrm{j})$; m é a média geral; $\mathrm{g}_{\mathrm{i}}$ e $\mathrm{g}_{\mathrm{j}}$ são os efeitos da capacidade geral de combinação do i-ésimo e do j-ésimo genitor, respectivamente; $s_{i j}$ é o efeito da capacidade específica de combinação para os cruzamentos entre os genitores de ordem i e j; e $\varepsilon_{\mathrm{ij}}$ é o erro experimental médio. Também foram estimados os coeficientes de correlação de Pearson entre os caracteres fenotípicos e a CGC e CEC em ambas as gerações. As análises foram realizadas com auxílio do programa Genes (CRUZ, 2006).

\section{Resultados e Discussão}

Acapacidade geral(CGC) e capacidade específica (CEC) de combinação dos caracteres avaliados foi significativa para as gerações $\mathrm{F}_{1}$ e $\mathrm{F}_{2}$, indicando a presença de efeitos gênicos aditivos e não aditivos influenciando na expressão (JOSHI et al., 2004; BERTAN et al., 2009). Para todos dos caracteres avaliados, em ambas as gerações, os valores dos quadrados médios da CGC foram superiores quando comparados a CEC, o que demonstra a maior contribuição dos efeitos gênicos aditivos na expressão dos caracteres estudados, os quais tendem a permanecerem em maior frequência após os efeitos da endogamia (POKHREL; BURDEN; DRAGAUTSEV, 1993; SINGH; SHARMA; SAIN, 2004; KAMALUDDIN et al., 2007). As magnitudes dos coeficientes de variação foram baixas, indicando alto grau de precisão experimental e confiabilidade das inferências estatísticas testadas.

$\mathrm{Na}$ análise de médias das populações e genitores (Tabela 2), observa-se que o cultivar Fundacep 50, tanto em $\mathrm{F}_{1}$ quanto em $\mathrm{F}_{2}$, foi efetivo em transmitir alelos favoráveis para número de espigas por planta (NEP), rendimento de grãos por planta (RGP) e massa de cem grãos (MCG), nos cruzamentos em que esteve presente. Em ambas as gerações, as menores estaturas de planta (EP) foram observadas quando a linhagem UTF 0605 esteve presente nos cruzamentos.

A capacidade geral de combinação representa, principalmente, a ação de genes de efeitos aditivos, possíveis de serem fixados nas populações segregantes (MATHER; JINKS, 1982). Assim, a escolha de genitores de trigo deve recair sobre aqueles com maior CGC (JOSHI et al., 2004), onde seriam maiores as chances de sucesso na recuperação de linhagens endogâmicas superiores. Os genitores Fundacep 50, BRS 208, BRS Timbaúva e Pampeano se destacaram com os valores mais elevados de CGC para RGP e número de grãos por espiga (NGE). Fundacep 50, BRS 208 também destacaram quanto a CGC para massa de cem grãos (Tabela 3) nas gerações $F_{1}$ e $F_{2}$. 
Tabela 1. Resumo da análise de variância dialélica das gerações $F_{1}$ e $F_{2}$ para estatura de planta $(E P)$, número de espigas por planta (NEP), número de grãos por espiga (NGE), massa de cem grãos (MCG) e rendimento de grãos por planta (RGP) de trigo, analisados pelo modelo proposto por Griffing (1956).

\begin{tabular}{|c|c|c|c|c|c|c|}
\hline \multirow{2}{*}{ Fontes de Variação } & \multirow{2}{*}{ G.L. } & \multicolumn{5}{|c|}{ Quadrados médios } \\
\hline & & EP & NEP & NGE & MCG & RGP \\
\hline \multicolumn{7}{|l|}{ Análise individual da geração $F_{1}$} \\
\hline Genótipos & 54 & $162,52 *$ & $3,52 *$ & $0,56^{*}$ & $3,72 *$ & $5,52 *$ \\
\hline CGC & 9 & $907,99 *$ & $8,28^{*}$ & $2,08^{*}$ & $20,13^{*}$ & $18,93^{*}$ \\
\hline CEC & 45 & $13,42 *$ & $2,56^{*}$ & $0,25^{*}$ & $0,44^{*}$ & $2,84 *$ \\
\hline Erro & 108 & 5,28 & 0,49 & 0,08 & 0,14 & 0,29 \\
\hline $\mathrm{CV}(\%)$ & & 3,9 & 7,5 & 1,2 & 12,2 & 7,5 \\
\hline \multicolumn{7}{|l|}{ Análise individual da geração $F_{2}$} \\
\hline Genótipos & 54 & $169,10^{*}$ & $3,25^{*}$ & $47,27^{*}$ & $0,03^{*}$ & $0,19^{*}$ \\
\hline CGC & 9 & $843,81 *$ & $9,37^{*}$ & $120,70^{*}$ & $0,15^{*}$ & $0,73 *$ \\
\hline CEC & 45 & $34,15^{*}$ & $2,02 *$ & $32,51 *$ & $0,01 *$ & $0,09 *$ \\
\hline Erro & 108 & 8,14 & 0,84 & 7,55 & 0,0008 & 0,01 \\
\hline $\mathrm{CV}(\%)$ & & 4,8 & 9,7 & 11,9 & 0,9 & 1,5 \\
\hline
\end{tabular}

*Significativo a 5\% de probabilidade de erro pelo teste F, GL - graus de liberdade, CGC- capacidade geral de combinação, CEC capacidade específica de combinação, CV(\%) - coeficiente de variação.

Fonte: Elaboração dos autores.

Na média das duas gerações, a linhagem UTF 0605 apresentou a melhor CGC $(-12,03)$ no sentido de reduzir a estatura de planta, devendo ser priorizada em cruzamentos com genitores suscetíveis ao acamamento. BRS Figueira apresentou baixos valores de CGC para RGP, MCG e NGE, o que demonstra o baixo potencial deste material em transmitir estas características às suas progênies. Entretanto, BRS Figueira evidenciou o melhor desempenho para o número de espigas por planta, justificável pelo fato de apresentar aptidão para duplo-propósito e ter sido selecionado para elevada capacidade de afilhamento; neste sistema de manejo BRS Figueira pode ser submetido a até três cortes ou pastejos e posterior colheita de grãos (EMBRAPA, 2007).

A magnitude e direção dos efeitos da CEC são de interesse na seleção de genitores em programas de melhoramento genético (MATHER; JINKS, 1971). Na Tabela 4 é possível observar inconsistência de desempenho da CEC ( $s_{\text {iii }}$ ) (valores positivos e negativos), quanto aos genitores, para os caracteres NEP e MCG, evidenciando presença de dominância bidirecional (CRUZ; VENCOVSKY, 1989). Valores negativos indicam desvios predominantemente positivos (LORENCETTI et al., 2005), atuando no sentido de aumentar os valores da característica. Portanto, os desvios negativos unidirecionais dos genitores, verificados para o caractere RGP, contribuem para o incremento deste nos híbridos. Também, quanto maior o valor absoluto da CEC do genitor, maior será a sua diversidade genética em relação à média dos demais genitores considerados no dialélo (CRUZ; VENCOVSKY, 1989). Nesse sentido, Fundacep 50, Pampeano e BRS Figueira destacaram-se pela divergência entre si e em relação aos demais genitores do dialélo.

O maior efeito médio da CEC para o caráter RGP, em ambas as gerações, foi observado nos cruzamentos BRS Timbaúva x BRS Figueira $\left(\mathrm{s}_{\mathrm{ij}}=\right.$ 1,41), UTF 0605 x Fundacep $50\left(\mathrm{~s}_{\mathrm{ij}}=1,15\right)$, BRS Guamirim x Pampeano $\left(\mathrm{s}_{\mathrm{ij}}=1,12\right)$, CD 115 x BRS Louro $\left(\mathrm{s}_{\mathrm{ij}}=1,10\right)$, BRS Guamirim $\mathrm{x}$ BRS $208\left(\mathrm{~s}_{\mathrm{ij}}=\right.$ 1,07), CD 115 x Abalone $\left(\mathrm{s}_{\mathrm{ij}}=1,05\right)$ e UTF 0605 $\mathrm{x}$ BRS Timbaúva $\left(\mathrm{s}_{\mathrm{ij}}=0,96\right)$, indicando o elevado potencial destas populações em produzir segregantes promissores. Além da elevada CEC para um caráter, é importante que pelo menos um dos genitores apresente elevada CGC (CRUZ; REGAZZI, 1997), pois assim o caráter desejado poderá ser mais rapidamente incorporado nas linhagens. 
(1)

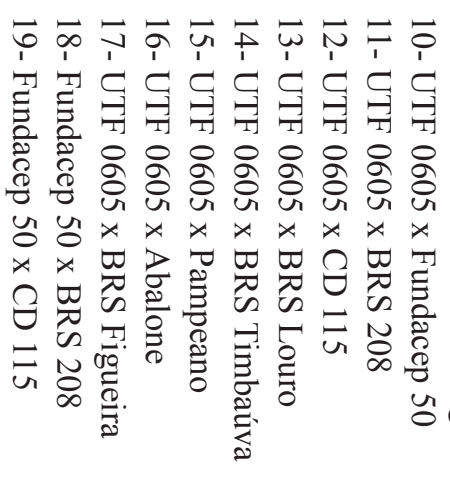

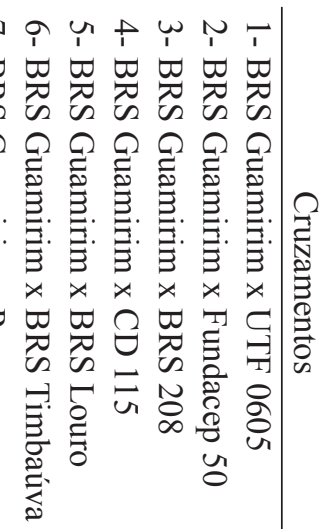

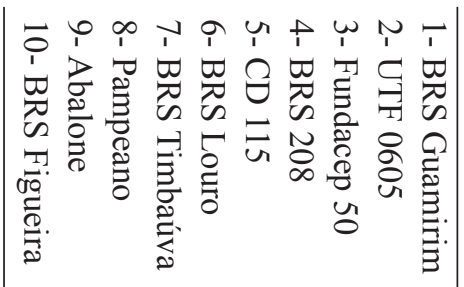

นุ

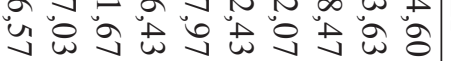

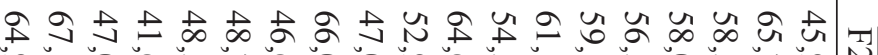

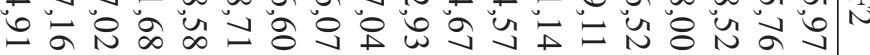

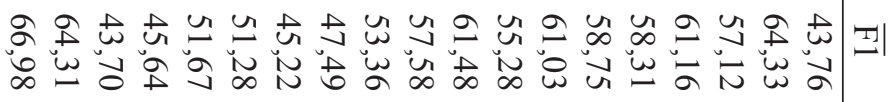

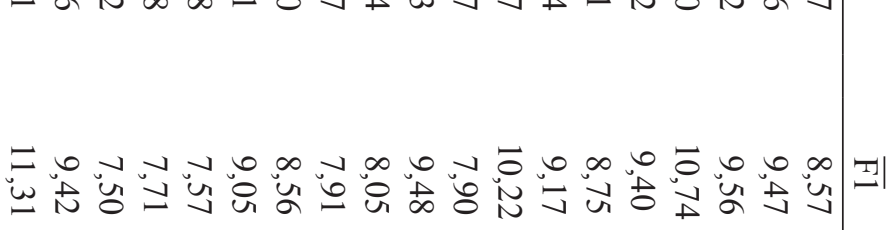

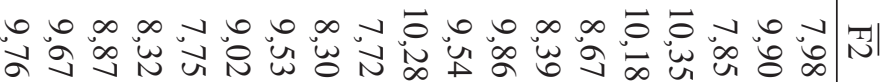

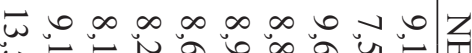
in

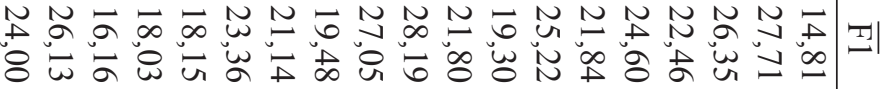

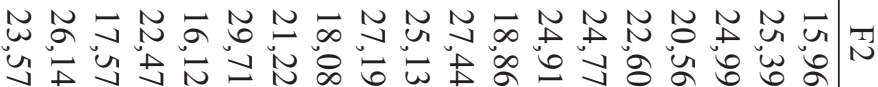

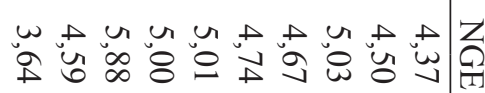

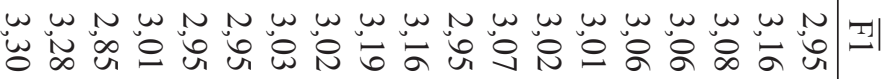

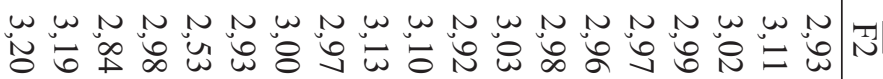

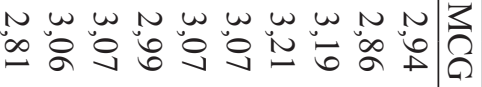

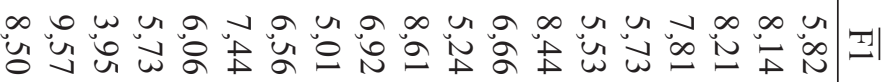
焉.

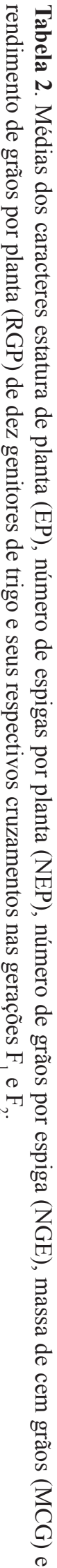




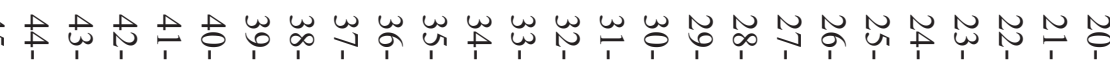

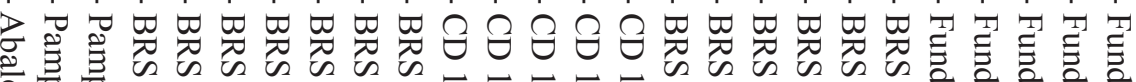

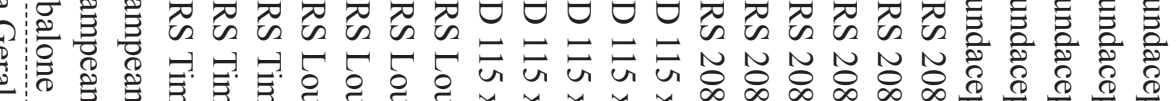
×

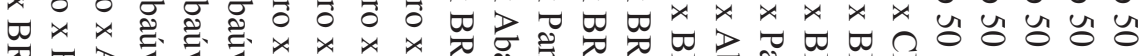

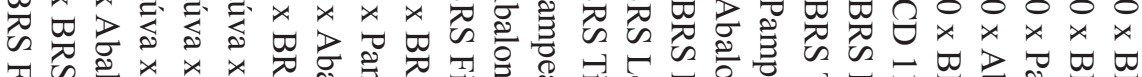

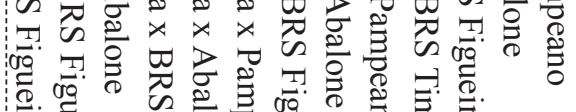
๑.

거 uు uे

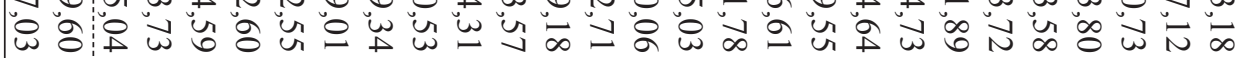

근 uू

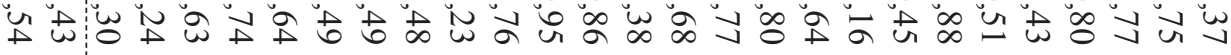

w

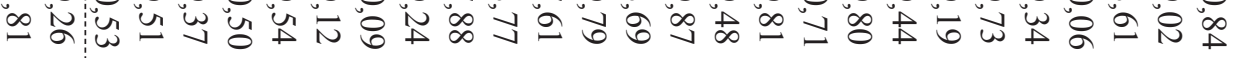

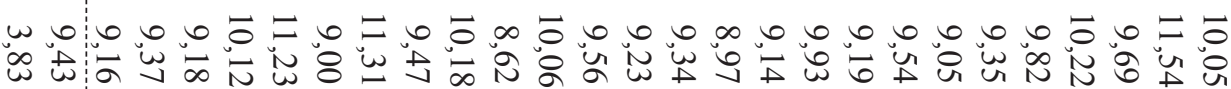

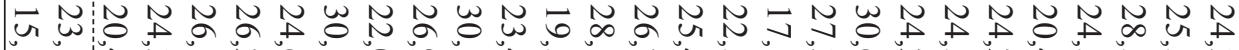

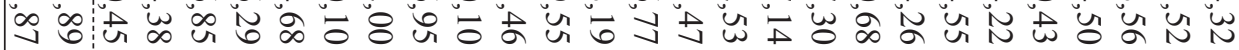

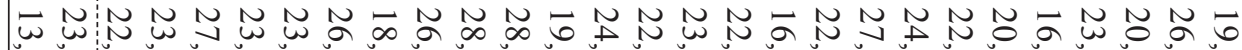
a

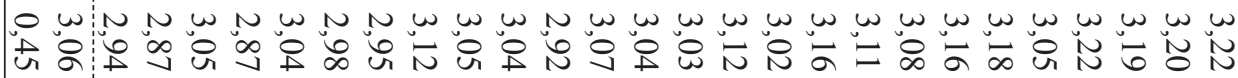

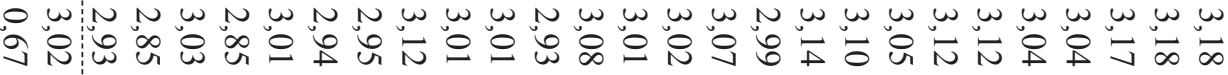

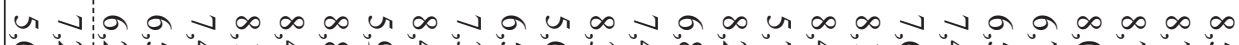

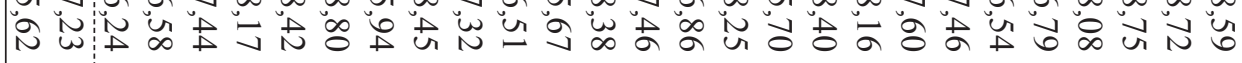

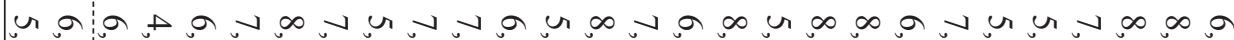

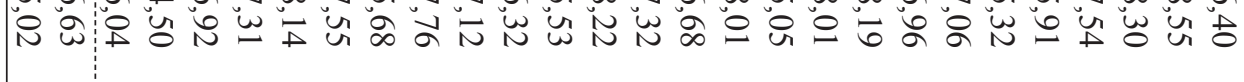




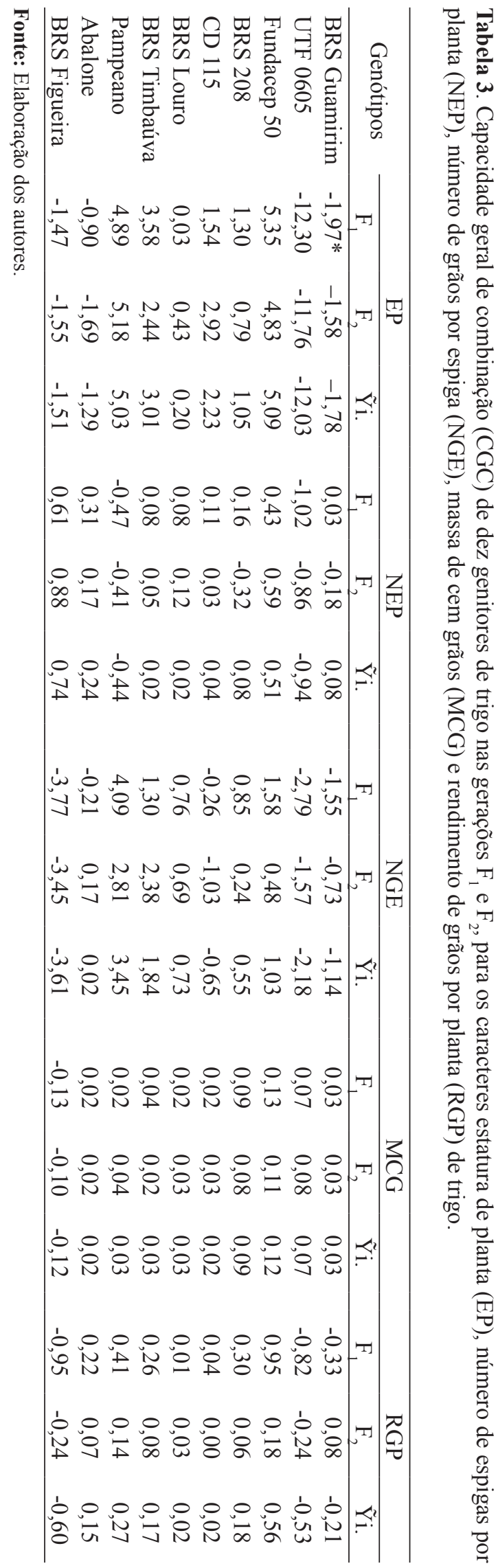




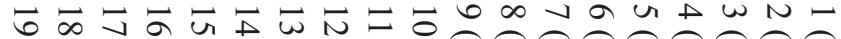

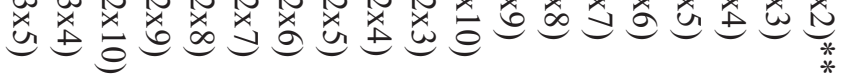

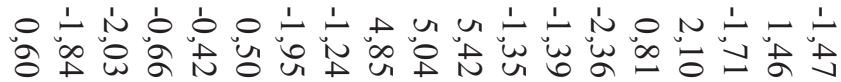

N⿴No 告

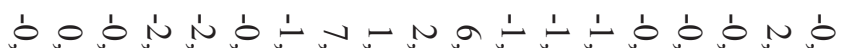

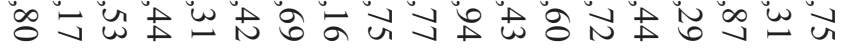

乡

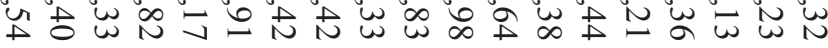

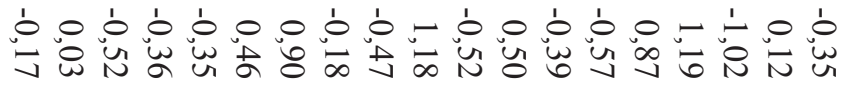

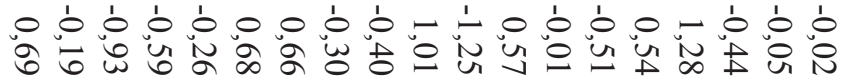

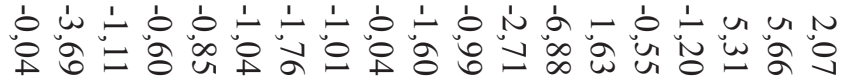

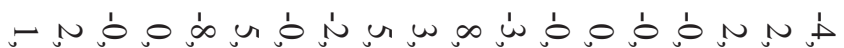
U.

○

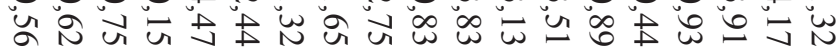

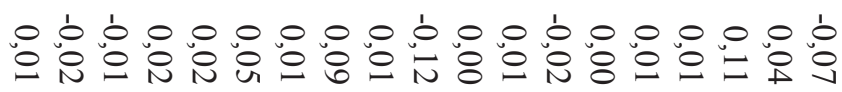

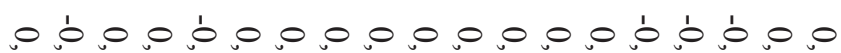
它

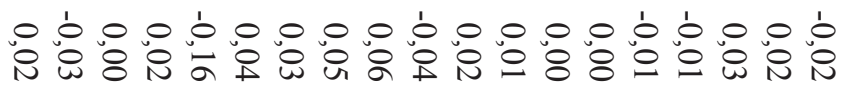

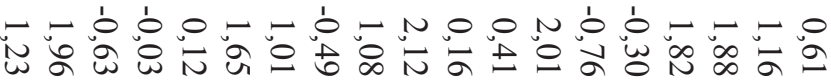
1
0
0

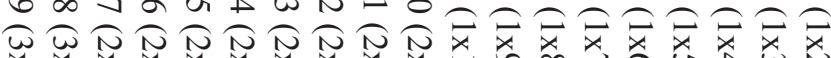

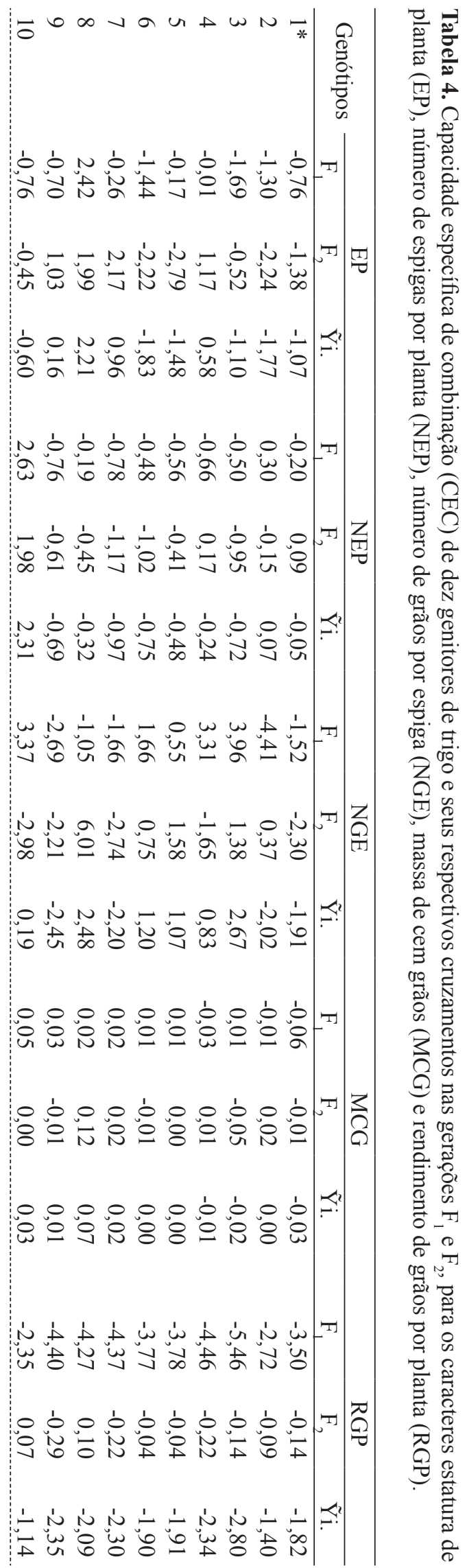




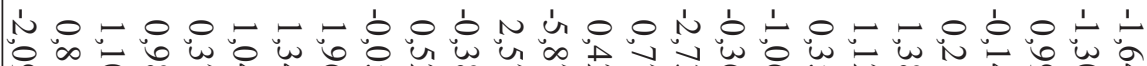

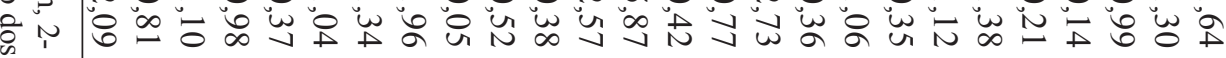

ñ $0_{0} n$ n n

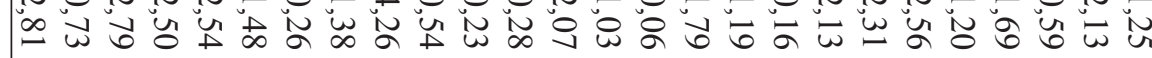

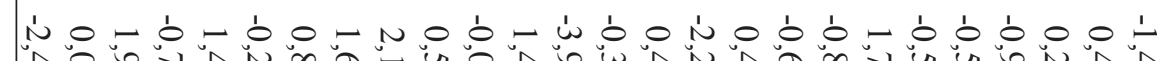

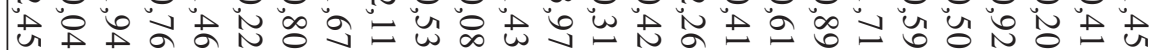

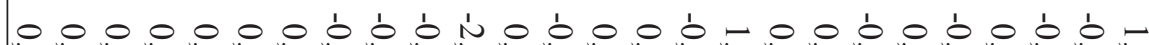

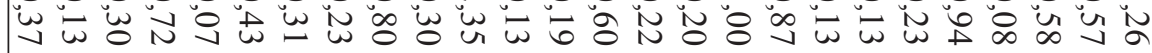

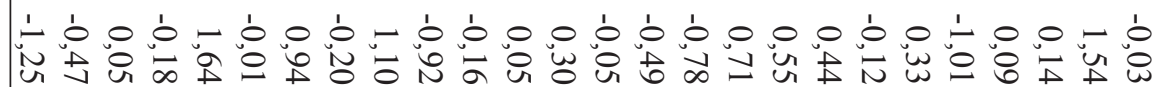

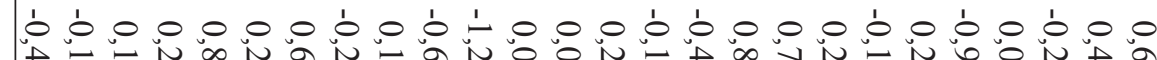

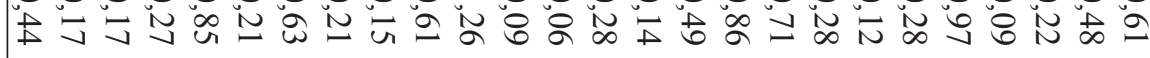

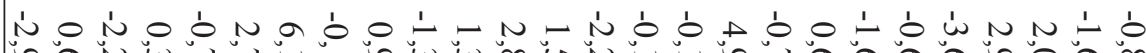

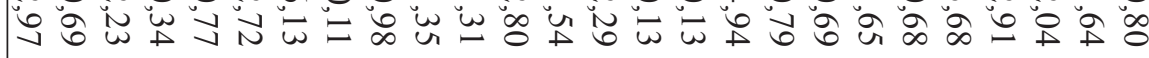

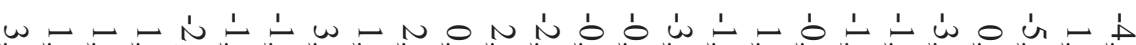

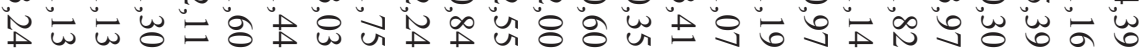

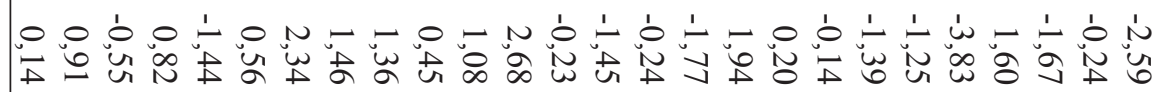

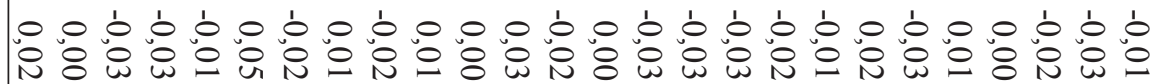

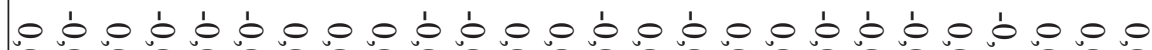

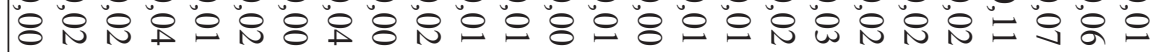

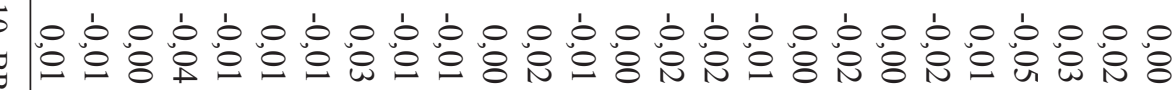

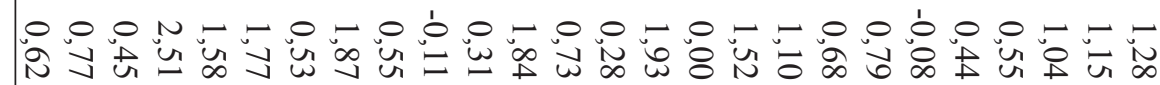

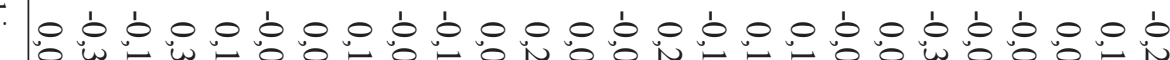
$\delta^{2}$ 
Resultados promissores de CEC para o caráter NGP foram observados nos cruzamentos BRS Guamirim x Fundacep 50, BRS Guamirim x BRS 208, UTF 0605 x BRS Timbaúva, Fundacep 50 x Abalone e BRS Louro x BRS Figueira (Tabela 4), sugerindo elevado grau de complementaridade alélica. Estes cruzamentos apresentaram ao menos um dos genitores com desempenho superior para esse caráter (Tabela 2) e um dos genitores com elevada CGC para NGE e/ou RGP (Tabela 3). Também, as combinações UTF 0605 x Fundacep 50, BRS 208 x Abalone e BRS Timbaúva x Abalone se destacam para o NEP, evidenciando serem ótimas fontes quando se busca constituições gênicas com alta capacidade de produção de espigas por $\mathrm{m}^{2}$. Para MCG, os valores de CEC não diferiram expressivamente entre si, indicando que os híbridos $F_{1}$ e populações $F_{2}$ tiveram o comportamento esperado com base na CGC de seus genitores (CRUZ; REGAZZI, 1997).

As correlações positivas, de moderada a elevada magnitude entre a CGC e rendimento de grãos por planta $\left(\mathrm{F}_{1}=0,75\right.$ e $\left.\mathrm{F}_{2}=0,81\right)$, número de grãos por espiga $\left(\mathrm{F}_{1}=0,61\right.$ e $\left.\mathrm{F}_{2}=0,60\right)$ e estatura de planta $\left(\mathrm{F}_{1}=0,99\right.$ e $\left.\mathrm{F}_{2}=0,98\right)$ (Tabela 5), indicam que a CGC deve ser considerada na escolha de genitores para comporem blocos de cruzamento, independente da geração avaliada.

Tabela 5. Valores de correlação entre as médias dos caracteres estatura de planta (EP), número de espigas por planta (NEP), número de grãos por espiga (NGE), massa de cem grãos (MCG) e rendimento de grãos por planta (RGP) de trigo e a capacidade geral de combinação (CGC) e capacidade específica de combinação (CEC) nas gerações $\mathrm{F}_{1}$ e $\mathrm{F}_{2}$.

\begin{tabular}{|c|c|c|c|c|c|c|}
\hline \multirow{2}{*}{\multicolumn{2}{|c|}{ Correlações }} & \multicolumn{5}{|c|}{ Caracteres } \\
\hline & & EP & NEP & NGE & MCG & RGP \\
\hline \multirow{2}{*}{$\mathrm{F}_{1}$} & CGC & $0,99 *$ & $0,49 *$ & $0,61^{*}$ & $0,38^{\mathrm{ns}}$ & $0,75^{*}$ \\
\hline & CEC & $0,26^{\mathrm{ns}}$ & $0,00^{\text {ns }}$ & $0,01^{\mathrm{ns}}$ & $0,03^{\text {ns }}$ & $0,04^{\text {ns }}$ \\
\hline \multirow{2}{*}{$\mathrm{F}_{2}$} & CGC & $0,98^{*}$ & $0,41^{*}$ & $0,60^{*}$ & $0,48 *$ & $0,81^{*}$ \\
\hline & CEC & $0,40^{\text {ns }}$ & $0,02^{\text {ns }}$ & $0,08^{\mathrm{ns}}$ & $0,10^{\text {ns }}$ & $0,02^{\text {ns }}$ \\
\hline
\end{tabular}

**Significativo ao nível de $1 \%,{ }^{*}$ Significativo ao nível de $5 \%,{ }^{\text {ns }}$ não significativo, pelo teste T para GL- 2 .

Fonte: Elaboração dos autores.

O desempenho dos caracteres avaliados não foi associado com a CEC, em ambas as gerações avaliadas, provavelmente devido às ações gênicas não aditivas. Tal resultado indica que a seleção de cruzamentos deverá recair sobre aqueles com elevada CEC, cujos genitores também apresentem média elevada para o caráter que estiver sendo melhorado e com pelo menos um genitor com elevada CGC (LORENCETTI et al., 2005; BENIN et al., 2009).

\section{Conclusões}

O genitor Fundacep 50 apresentou elevada capacidade geral de combinação para rendimento de grãos por planta e massa de grãos. Pampeano e
BRS Timbaúva maximizaram o número de grãos por espiga e BRS Figueira foi bom combinador para o número de espigas por planta.

Os cruzamentos BRS Timbaúva x BRS Figueira, BRS Timbaúva x UTF 0605, Fundacep 50 X UTF 0605, BRS Guamirim x Pampeano, BRS Guamirim x BRS 208, CD 115 x Abalone, apresentam maior probabilidade de produzir populações com elevada frequência de segregantes promissores, para o rendimento de grãos e seus componentes.

Selecionar combinações híbridas de trigo com superior capacidade geral de combinação maximiza o desempenho do rendimento de grãos por planta, número de grãos por espiga e estatura de planta, independente da geração avaliada. 


\section{Agradecimentos}

Ao Conselho Nacional de Desenvolvimento Científico e Tecnológico (CNPq) e à Fundação Araucária, pelo apoio financeiro.

\section{Referências}

BARBIERI, R. L.; CARVALHO, F. I. F.; BARBOSA NETO, J. F.; CAETANO, V. R.; MARCHIORO, V. S.; AZEVEDO, R.; LONRECETTI, C. Análise dialélica para tolerância ao vírus-do-nanismo-amarelo-da-cevada em cultivares brasileiras de trigo. Pesquisa Agropecúaria Brasileira, Brasília, v. 36, n. 1, p. 131-135, 2001.

BENIN, G.; OLEGÁRIO, G. S.; PAGLIOSA, E. S.; LEMES, C.; SIGNORINI, A.; BECHE, E.; CAPELIN, M. A. Capacidade de combinação em genótipos de trigo estimada por meio de análise multivariada. Pesquisa Agropecuária Brasileira, Brasília, v. 44, n. 9, p. 1145 1151, 2009.

BERTAN, I.; CARVALHO, F. I. F.; OLIVEIRA, A. C.; BENIN, G.; VIEIRA, E. A.; VALÉRIO, I. P. Morphological, pedigree, and molecular distances and their association with hybrid wheat performance. Pesquisa Agropecuária Brasileira, Brasília, v. 44, n. 2, p. 155-163, 2009.

BHERING, S. B.; SANTOS, H. G. dos; BOGNOLA, I. A.; CÚRCIO, G. R.; MANZATTO, C. V.; CARVALHO JUNIOR, W. de; CHAGAS, C. da S.; ÁGLIO, M. L. D.; SOUZA, J. S. de. Mapa de solos do Estado do Paraná: legenda atualizada. Rio de Janeiro: EMBRAPA/IAPAR, 2008. $74 \mathrm{p}$.

COMISSÃO SUL BRASILEIRA DE PESQUISA DE TRIGO. Recomendações da comissão sul-brasileira de pesquisa de trigo. Passo Fundo: EMBRAPA-CNPT, 2004. $150 \mathrm{p}$.

CRUZ, C. D.; REGAZZI, A. J. Modelos biométricos aplicados ao melhoramento genético. 2. ed. Viçosa: UFV, 1997. 390 p.

CRUZ, C. D. Programa genes: aplicativo computacional em genética e estatística. Viçosa: UFV, 2001. 648 p.

CRUZ, C. D.; VENCOVSKY, R. Comparação de alguns métodos de análise dialélica. Revista Brasileira de Genética, Ribeirão Preto, v. 12, n. 2, p. 425-438, 1989.

DHONDE, S. R.; KUTE, N. S.; KANAWADE, D. G.; SARODE, N. D. Variability and characters association in the wheat (Triticum aestivum). Agriculture Science Digest, Karnal, v. 20, n. 2, p. 99-101, 2000.
EMPRESA BRASILEIRA DE PESQUISA AGROPECUÁRIA - EMBRAPA. Cereais de inverno de duplo propósito na integração lavoura-pecuária: aveia, cevada, centeio, trigo, triticale. Passo Fundo: Embrapa Trigo, 2007. 24 p. (Embrapa Trigo. Documentos, 79).

FARSHADFAR, E.; MAHJOURI, S.; AGHASEE, M. Detection of epistasis and estimation of additive and dominance components of genetic variation for drought tolerance in durum wheat. Journal of Biological Sciences, Jahrgang, v. 8, n. 3, p. 598-603, 2008.

GRIFFING, B. A concept of general and specific combining ability in relation to diallel crossing systems. Australian Journal of Biological Sciences, Melbourne, v. 9, n. 4, p. 463-493, 1956.

HASNAIN, Z.; ABBAS, G.; SAEED, A.; SHAKEEL, A.; MUHAMMAD, A.; RAHIM, M. A. Combining ability for plant height and yield related traits in wheat, Triticum aestivum L. Journal of Agricultural Research, Punjab, v. 44, n. 3, p. 167-173, 2006.

JOSHI, S. K.; SHARMA, S. N.; SINGHANIA, D. L.; SAIN, R. S. Combining ability in the $\mathrm{F} 1$ and $\mathrm{F}_{2}$ generations of diallel cross in hexaploid wheat (Triticum aestivum L. em. Thell). Hereditas, Sweden, v. 141, n. 2, p. 115-121, 2004.

KAMALUDDIN, R. M.; SINGH, L. C. P.; MALIK, Z.; JOSHI, A. K. Combining ability analysis for grain filling duration and yield traits in spring wheat (Triticum aestivum L. em. Thell.). Genetics and Molecular Biology, São Paulo, v. 30, n. 2, p. 411-416, 2007.

KRYSTKOWIAK, K.; ADAMSKI, T.; SURMA, M.; KACZMAREK, Z. Relationship between phenotypic and genetic diversity of parental genotypes and the specific combining ability and heterosis effects in wheat (Triticum aestivum L.). Euphytica, Wageningen, v. 165, n. 3, p.419-434, 2009.

LORENCETTI, C.; CARVALHO, F. I. F.; BENIN, G.; MARCHIORO, V.; OLIVEIRA, A. C.; SILVA, J. A. G.; HARTWIG, I.; SCHMIDT, D. A. M.; VALÉRIO, I. P. Capacidade combinatória e heterose em cruzamento dialélico de Aveia (Avena sativa L.). Revista Brasileira de Agrociência, Pelotas, v. 11, n. 2, p. 143-148, 2005.

MATHER, K.; JINKS, J. L. Biometrical genetics: the study of continuous variation. 3. ed. London: Chapman and Hall, 1982. 396 p.

Biometrical genetics: the study of continuous variation. 2. ed. London: Chapman and Hall, 1971. 382 p.

MENON, U.; SHARMA, S. N. Genetics of yield determining factors in spring wheat over environments. Indian Journal Genetic, New Delhi, v. 57, n. 3, p. 301306, 1997. 
PFANN, A. Z.; FARIAI, M. V.; ANDRADE, A. A. de; NASCIMENTO, I. R. do; FARIA, C. M. D. R.; BRINGHENTTI, R. M. Capacidade combinatória entre híbridos simples de milho em dialélo circulante. Ciência Rural, Santa Maria, v. 39, n. 3, p. 635-641, 2009.

POKHREL, P. R.; BURDEN, A. M.; DRAGAUTSEV, V. A. Harvest index and grain sink size in wheat. Indian Journal of Genetics and Plant Breeding, v. 57, n. 4, p. 361-365. 1993.

SINGH, H.; SHARMA, S. N.; SAIN, R. S. Combining ability for some quantitative characters in hexaploid wheat (Triticum aestivum L. em. Thell). In: INTERNATIONAL CROP SCIENCE CONGRESS, 4., 2004, Brisbane. Proceedings... Brisbane, Austrália: The Regional Institute Ltd, 2004.
TOPAL, A.; AYDIN, C.; AKGÜN, N.; BABAOĞLU, M. Diallel cross analysis in durum wheat (Triticum durum Desf.): identification of best parents for some kernel physical features. Field Crops Research, Amsterdam, v. 87, n. 1, p. 1-12, 2004.

YANG, Y. H.; DUDOIT, S.; LUU, P.; LIN, D. M.; PENG, V.; NGAI, J.; SPEED, T. P. Normalization for cDNA microarray data: a robust composite method addressing single and multiple slide systematic variation. Nucleic Acids Research, London, v. 30, n. 4, p. 1-10, 2002. 